This item was submitted to Loughborough's Research Repository by the author.

Items in Figshare are protected by copyright, with all rights reserved, unless otherwise indicated.

\title{
Semantic web in manufacturing
}

PLEASE CITE THE PUBLISHED VERSION

http://dx.doi.org/10.1243/09544054JEM1399

PUBLISHER

Professional Engineering Publishing @ IMechE

VERSION

VoR (Version of Record)

LICENCE

CC BY-NC-ND 4.0

REPOSITORY RECORD

Khilwani, Nitesh, Jennifer A. Harding, and Alok K. Choudhary. 2019. "Semantic Web in Manufacturing". figshare. https://hdl.handle.net/2134/9519. 
This item was submitted to Loughborough's Institutional Repository (https://dspace.lboro.ac.uk/) by the author and is made available under the following Creative Commons Licence conditions.

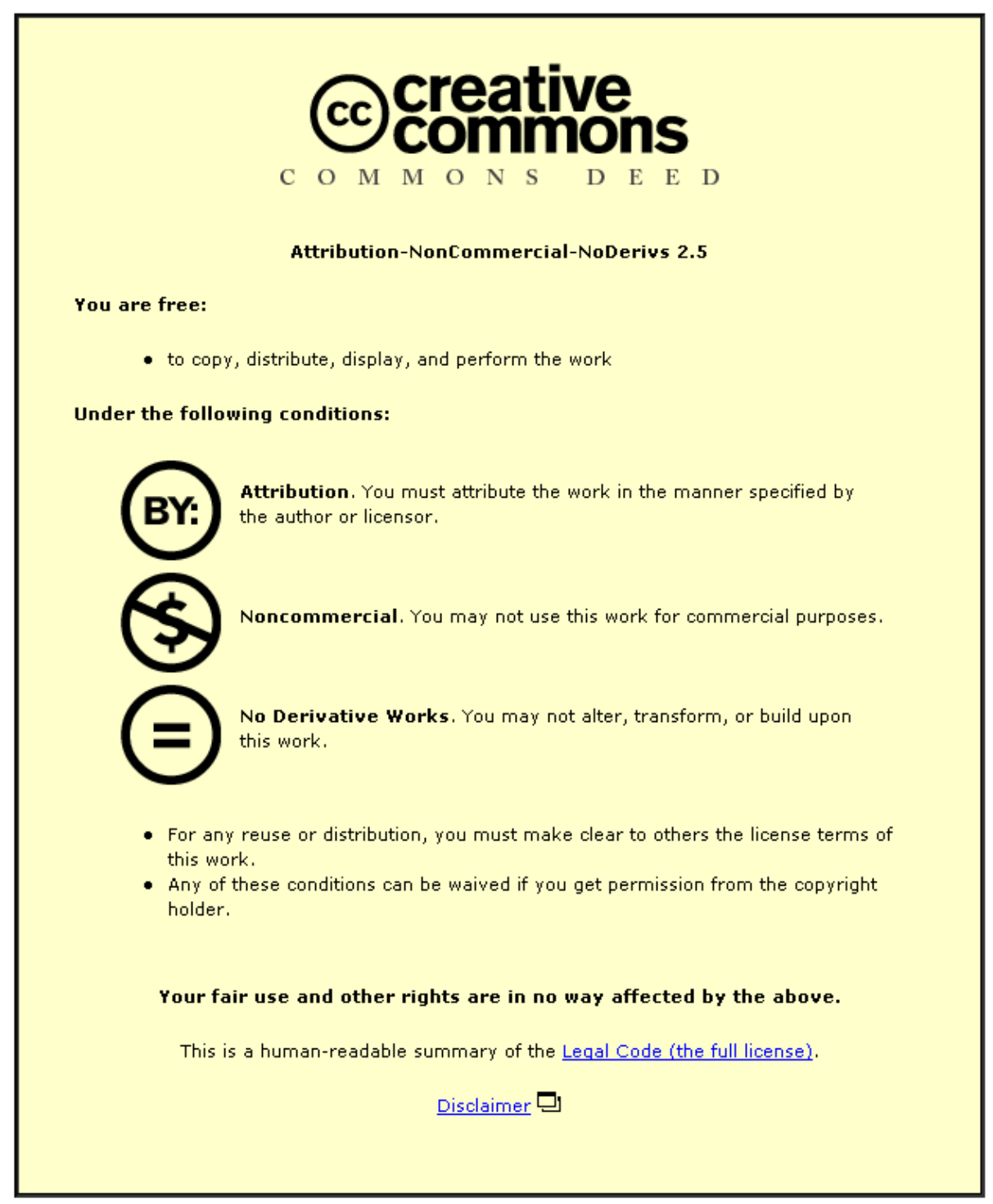

For the full text of this licence, please go to: http://creativecommons.org/licenses/by-nc-nd/2.5/ 


\title{
Semantic web in manufacturing
}

\author{
N Khilwani, J A Harding*, and A K Choudhary \\ Wolfson School of Mechanical and Manufacturing Engineering, Loughborough University, Loughborough, UK
}

The manuscript was received on 15 October 2008 and was accepted after revision for publication on 11 March 2009.

DOI: 10.1243/09544054JEM1399

\begin{abstract}
Advances in manufacturing systems include attempts to create collaborative networks for enterprise integration and information interoperability. To achieve collaboration and sharing effectively, various networking technologies have been proposed in the literature. The web has emerged as a basic entity for interconnecting man and machine and almost all parts of the enterprise community are being reshaped to exploit the opportunities that it offers. Apart from web technology, there are various other tools and techniques that have attracted research communities for representing data in ways that both machines and humans can understand. Semantic web, the second-generation web technology, is enriched by machine-processable information to support the users in their tasks. This paper presents the vision of the semantic web and describes ontologies and associated metadata as the building blocks of the semantic web. It reviews the literature dealing with the application of the semantic web and ontology in the broad domain of manufacturing. First, brief details about key enablers, i.e. web services, semantic web, semantic services, and ontology, are presented. Then the implementation of these approaches in different sectors of manufacturing is discussed. A knowledge base for all the information resources concerned with the manufacturing domain is also built up in this paper. An ontology model for a knowledge base of information resources is designed in Protégé software, which can be used for storing and searching information about authors, journals, blogs, newspapers, and many other sources of information.
\end{abstract}

Keywords: manufacturing, web technology, ontology, semantic web, protégé

\section{INTRODUCTION}

Amid the immense pressure of continuous improvement in productivity, responsiveness, and flexibility, manufacturing firms are facing huge challenges from their consumer market to satisfy individual customer requirements. Manufacturers are striving to meet these requirements by focusing their core competencies to enable them to compete effectively and efficiently to the best of their ability. The traditional view of an enterprise, with clear boundaries, limited relationships with others, and a strong internal focus on efficiency and quality is no longer adequate [1]. Today, firms aim to improve their competitive edge by focusing on core competencies and outsourcing all other functions. In such environments, organizational barriers break

*Corresponding author: Wolfson School of Mechanical and Manufacturing Engineering, Loughborough University, Ashby Road, Loughborough LE11 3TU, UK.

email: j.a.harding@lboro.ac.uk down, partnerships with suppliers, clients, and even competitors are common place and efficiency and quality are considered beyond enterprise boundaries. The current trend among manufacturing firms is to form collaborative networks to succeed and achieve business goals [2].

The 'automotive industry' is one of the best examples to show this transition. In order to compete with the global giants, the automotive sector has concentrated on core competencies and collaborations between organizations that compliment their skills and core activities [3]. Companies adopt this new policy by sharing designs, developments, and platforms and thus reduce the burden of costs associated with the development of non-core activities [4]. This revolution started in the recession of the early 1990s, with the massive move towards outsourcing of non-core activities such as information technology, public relations, human resources, etc. This step was an impressive move in the automotive sector that resulted in massive reductions of fixed 
costs, overheads, and manpower, thereby enabling the survival of companies.

Global manufacturing increases awareness of markets and competition, stimulating the generation and sharing of vast quantities of information and thus increasing the pressure on the worldwide manufacturing community to exploit the power of the latest technological advancements to differentiate itself from the competition [5]. Manufacturing enterprises are constantly aiming successfully to address these growing challenges through the influence and impact of information technology (IT). The most pervasive and bedevilling IT challenge in achieving their goal is to provide correct and timely information to the right people at the right time. Information and knowledge are considered to be the lifeblood of a firm, as shown in Fig. 1, as they underpin all the processes of a manufacturing organization. However, information and knowledge resources are inherently distributed and are often available in different and sometimes incompatible formats, e.g. electronic documents, databases, hard copy, etc. [6]. Moreover, it is difficult to accumulate, maintain, and modify knowledge during business processes in which requirements change frequently. Amalgamating information so that it can be shared and exploited across multiple business functions and processes clearly has attractions, as it reduces the potential for errors caused by data duplications and resulting inconsistencies. Enterprises often use in-house developed software created specifically by their own programming staff or by a consultant. However, huge consolidated and single-source approaches increase

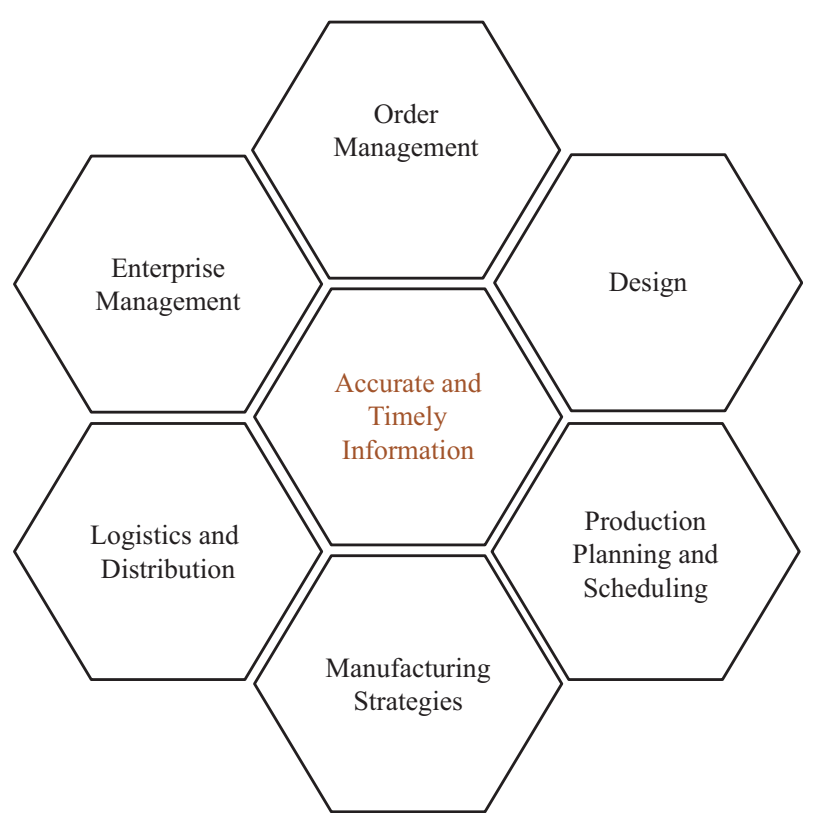

Fig. 1 Influence of information in manufacturing complexity and maintenance challenges $[\mathbf{7}, \mathbf{8}]$. Therefore, emerging technologies attempt to share and effectively utilize a full range of data, knowledge, and information $[\mathbf{9}, \mathbf{1 0}]$. In this era of knowledgebased manufacturing, knowledge management techniques have attracted attention from both companies and academics.

Despite growing interest and efforts, web-based information services are still primitive in their functionality. Today's web arranges the information syntactically, assuming them to be semantically homogeneous, but this can commonly cause problems and misunderstandings [11]. This downside means that most of the information must primarily be used and interpreted by humans, rather than by machines. The availability of information that requires human interpretation does not necessarily solve the complex problem of conveying the right information to the right person at the right time. To overcome this problem, researchers are focusing on semantic web concepts and tools that enable computers automatically to process and understand the information [12]. The primary benefit of this new vision of Berners-Lee et al. [13] is to represent the web resources in formalisms that both machines and humans can understand. Although the available search engines are quite powerful, they still focus on physical connectivity that often provides too large and inadequate (insufficiently targeted) list of resources. Thus, the objective for semantic enabled machine processable information is that it be used to guide the search towards relevant resources and improve both precision and recall.

The growing access to heterogeneous and independent data repositories has attracted many research communities to explore ways of representing data in ways that they can be shared and processed automatically using scripts or programs [14]. The idea is to provide explicit semantic descriptions for all information resources and encode them in an unambiguous and machine understandable form. However, a semantic description itself is not able to solve the problem of integration and combination of information from diverse sources. In order to make the data understandable to users as well as programs, it is also necessary to build an ontology of the terms relevant to the field under consideration [15]. Thus, the semantic web research community is also exploiting ontologies for semantically describing the domains associated with the given information sources [16]. Ontology is considered to be the backbone of the semantic web and the keystone for the web's automated tasks such as searching, merging, sharing, maintaining, customizing, and monitoring. It is used to provide machine processable semantics for data and information sources that can be used by 
an agent (software or human), application, or other information resources.

The primary benefit of this new vision should be to make the information understandable to both users and programs, as then it will become possible for firms to understand the semantics of other firms and communicate and share their information with others. Semantic web services are used as a platform for sharing semantic enabled information over the web [12]. The present paper considers the broad area of semantic web technology implemented in manufacturing. The objective of this paper is to provide a comprehensive review of the varied research work that has been done in implementing semantic web and ontology in the broad domain of manufacturing. The remainder of this paper is as follows. Section 2 provides brief details of the key enablers used in literature for manufacturing system integration. Section 3 details the related research work done to implement semantic web and ontology in the broad domain of manufacturing. Section 4 illustrates the domain of manufacturing where companies seek to use these tools for enhancing their co-operative and competitive edge in the market. In section 5 , an ontology model for information resources is developed and its real-life implementation is described. Finally, section 6 concludes the paper.

\section{KEY ENABLERS FOR INTELLIGENCE IN MANUFACTURING}

Today manufacturing enterprises operate in an environment where markets frequently change, new technologies continually emerge, and competition is fierce at a global scale [17]. To cope with such competitive issues, firms are trying to create collaborative manufacturing networks for enterprise integration and information interoperability [2]. In order to achieve this collaboration and sharing effectively, various networking technologies have been proposed. Moreover, the combination of computer and networking technologies has effectively supported the transfer and exchange of knowledge among enterprises. It is commonly accepted that it is the ubiquity of web technology and the internet that initiated and made possible the integration of diverse systems and applications inside an enterprise as well as between different enterprises. Subsequently, web services were designed to improve the interoperability across companies and wide area network. Initially, these services were basically made available to cope with differences in the structure and syntax of heterogeneous data bases and web programs. Later, the ability of web services was enhanced by creating semantic mark-ups for web services that make them machine understandable and user apparent. These mark-ups are built using ontologies that represent particular domains through their concepts and the semantic relations between them $[13,14]$.

Considering the entire progress made in the field of manufacturing system integration, this section provides brief details about the key enablers that have great potential for automating enterprise integration.

\subsection{Web technology}

Web is an emerging technology used to interchange hitherto-inaccessible information sources by making them electronically available. This technology provides the combined features of multi-media, computer networking, distributed computing, databases, etc. using the internet. It provides significant interactive media for information presentation in business and daily life. Owing to its open standards, ease of use, and ubiquity, it has been widely employed to associate different manufacturing activities such as marketing, design, process planning, production, etc. [11].

\subsection{Web services}

Web services are the set of functionalities used to enhance the potential of web technology by providing ways of automated program communication and discovery of services. According to Tidwell [18], a web service is a self-defined, self-describing, modular application that can be published, located, and invoked across the web. It is basically a networking technology used to connect computers and devices with each other for exchanging information and combining it in new ways. Web services are loosely coupled computing tasks communicating over the internet using a specific description language. Generally, hypertext transfer protocol (HTTP) and extensive markup language (XML) are used as service description languages required for application integration [19]. This ubiquitous technology has been widely employed for building a robust, sharable, and extensible collaborative architecture over the internet. Moreover, it has provided new opportunities for firms to facilitate the sharing of resources and therefore allows them to enjoy the benefits of integration.

\subsection{Semantic web and semantic enabled web services}

The current web technology supports global network collaboration by providing platform independence to publish and access data. Humans are capable of using the web to carry out tasks. However, a computer cannot accomplish the same tasks without human direction because web pages are designed to be read by people, not machines. Tasks are therefore 
carried out based on individual programmer's or interpreter's understanding of the semantics of language from available descriptions to guide the computers [11]. In order to overcome this drawback, web services are enabled with formal and declarative semantic markups automatically to discover, invoke, compose, and monitor the associated processes. Such web services are complemented with ontologybased semantic markups that are known as semantic-based web services [20].

The semantic web has added a new level to web services $[11]$. The concept of the semantic web is, without any doubt, gaining attention in both industry and academia. It is defined as the conceptual structuring of the semantics of data in a machine readable way that enables web entities to interoperate with each other, dynamically discover resources, extract knowledge, and solve problems [21]. The declaration of domain knowledge in a machine readable way enhances the understandability of disparate information. Although the semantic web has been proposed as the way to provide machine understandable and interpretable semantics for computers, it is unable to provide a suitable infrastructure for interaction and encapsulation of processes and skills. Therefore, web services are needed to address these requirements directly by providing an interface for encapsulating and unifying the technologies. The concept of semantic web services was proposed for enabling a system automatically to discover, invoke, compose, and monitor the associated processes and system. Figure 2, which is a development of work initially presented in Burstein [12], portrays the evolution of semantic web services. Recently, semantic web services have received a great deal of attention for their ability to make interactions among firms more flexible and automated. They have been used to annotate the information available on the web for automated processing and information integration. Semantic web services have been used in the following research directions [22]:

(a) provide common syntax for machine understandable statements;

(b) establish common vocabulary;

(c) develop repository of computer manipulatable data having well defined semantics.

\subsection{Ontology}

Semantic web services are web services whose descriptions are in languages that have well-defined semantics. Ontologies are used for defining the semantics present in the concerned domain and for sharing them among people, databases, and applications. The term 'ontology' has been coined from philosophy, as a branch of metaphysics concerned with the systematic explanation of existence. Owing to its strong implications for conception of reality, it has gained much interest in artificial intelligence for defining the basic terms and relationships comprising the vocabulary of a topic area as well as the rules for combining terms and relations to define extensions to the vocabulary [23]. Ontology has been defined by several researchers in different ways but the definition that is most widely referenced is 'an explicit and formal specification of a shared conceptualization', where explicit indicates that it is comprised of concepts, properties, relationships, functions, axioms, and constraints [24]. Similarly, 'formal' is used because it is machine readable and interpretable. Conceptualization shows that it is an abstract model and a simplified view of the existing

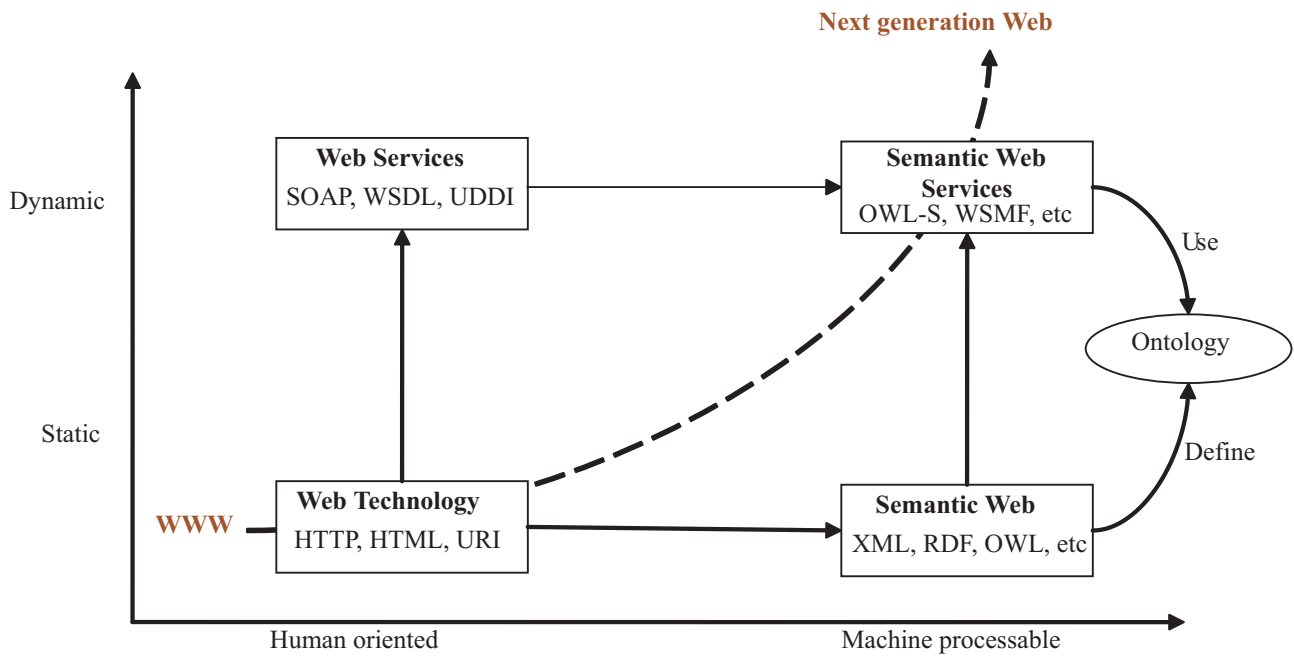

Fig. 2 Evolution of semantic web services from web technology 
Table 1 Definition of ontology proposed in literature [25, 26]

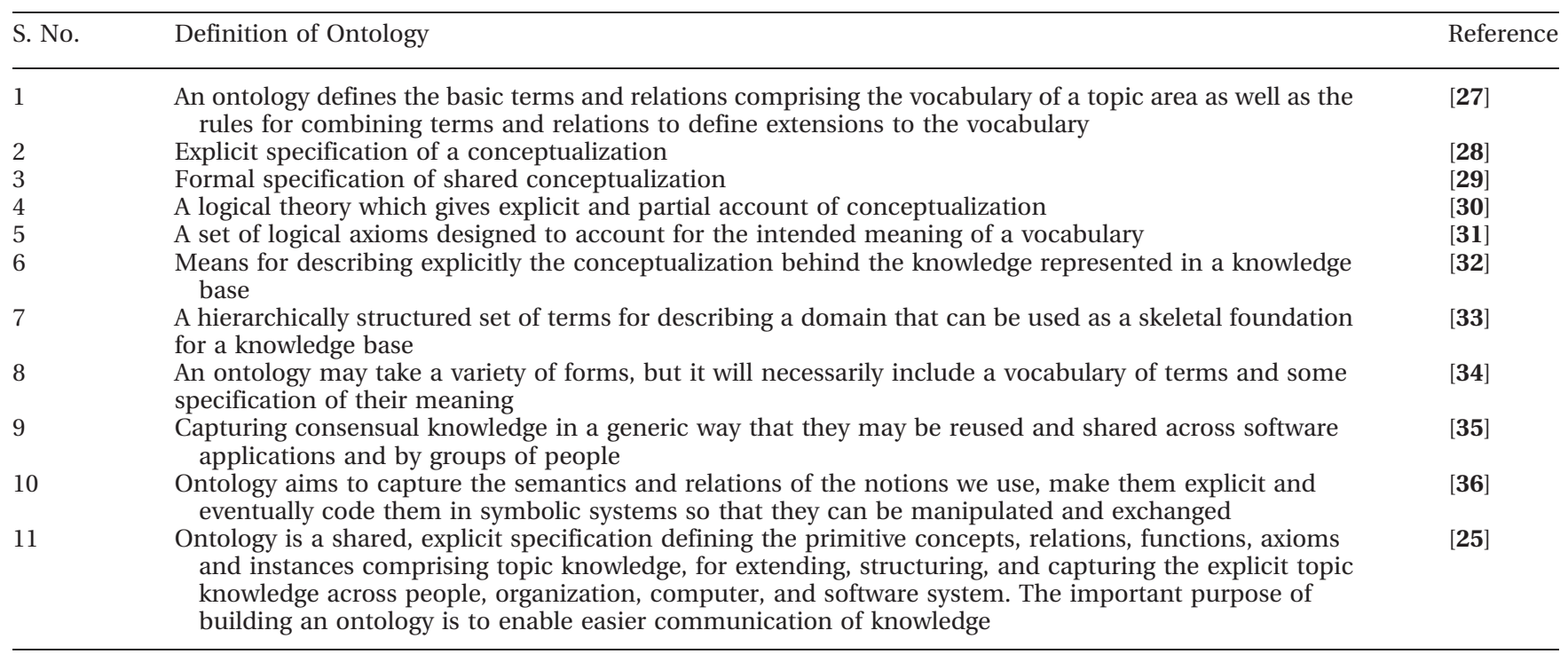

things it represents and that the view is shared, as there is consensus about the information that is acknowledged by a group of experts. In short, it is a set of concepts, its taxonomy, interrelations, and the rules that govern such concepts. Further definitions provided by other researchers are provided in Table 1.

Ontologies have been developed and used for the following purposes [26]

(a) share knowledge: sharing the structure of information among software agents and people;

(b) reuse knowledge: reusing it for other systems operating in a similar domain;

(c) make assumption about a domain: for easier communication.

\subsection{Semantic-enabled multi-agent system}

Agent-based technology is a paradigm of information and communication technology [37]. It has received significant attention in manufacturing domains to realize important properties of autonomy, responsiveness, redundancy, and openness [38]. Over the past few years this technology has been applied in various manufacturing areas such as supply chain management, manufacturing planning, scheduling, and execution control. It has been implemented to carry out all small and large, simple, and complicated tasks in manufacturing where agents can be enabled and empowered to communicate and cooperate with each other.

The agents cooperate and communicate by sending messages through web services on the internet. However, with the growth of heterogeneous databases and independent data repositories, such services are only for displaying external forms of the information rather than for achieving the user's purpose effectively. Ontologies have been developed to support the exchange of meaningful information across autonomous entities that can organize and use information heterogeneously [39]. Agents may be human or machines that use their domain ontology to share and exchange knowledge and information. Semantic web services are used for sharing of heterogeneous and autonomous knowledge sources in a scalable, adaptable, and extensible manner [40]. The use of semantic web services in manufacturing enables agents to be used for automatic discovery, composition, and execution of services that can implement the required manufacturing processes.

The objective of the current paper is to present a comprehensive overview of semantic web technology's implementations in manufacturing and to demonstrate the use of this technology in sharing knowledge of information resources. The next section therefore provides brief details of the related research work that has been done to implement semantic web and ontology in the broad domain of manufacturing.

\section{RELATED WORK}

The previous sections show that a major challenge for manufacturing enterprises is how to deal with their highly complex, ever-growing information assets. The overwhelming amount of information in the manufacturing sector increases the need for employing knowledge intensive methodologies that 
facilitate meaningful acquisition and sharing of information. The management of this asset is considered to be the main source of competitive advantage for corporations. Its availability, ability to exchange it seamlessly and process it quickly are the basic factors responsible for meeting the escalating expectations of customers in the global market.

Nabuco et al. [41], presented a preliminary study aimed at identifying the basic requirements for knowledge sharing. Six basic components identified for knowledge sharing approaches are acquisition, modelling, reusability, retrieval, publishing, and maintenance. In the past few decades, the manufacturing community has been continuously implementing communication and information technology for sharing and exchanging knowledge. Initially, offline technologies such as client server architectures and local area networks were used to enable communication from one specific application to another. However, an increased number of manufacturing entities and matured use of information technology in manufacturing has made it difficult to provide separate programs for linking each entity of manufacturing. Thus, offline knowledge sharing was replaced by real-time technology, i.e. web technology and internet. Web technologies have been widely employed in manufacturing to underpin pervasively networked work that interconnects entities in various ways. This section delineates the work of researchers and practitioners in replacing traditional offline knowledge sharing methods with online real-time collaboration in the global economy.

The web has emerged as a basic entity for interconnecting man and machine and almost all parts of the manufacturing community are being reshaped to exploit the opportunities offered by the web. As part of an effort to improve cooperation, communication, and collaboration, the manufacturing community is providing a wide spectrum of online services. Yang and Xue [42] delineate the work of researchers and practitioners in replacing traditional offline knowledge sharing methods with online real-time collaboration in the global economy. This paper gives a comprehensive review of recent research done in developing web-based manufacturing. Web technology is used to coordinate various manufacturing activities performing in distributed environments. Various computer and networking technologies are employed for developing web-based manufacturing systems such as:

(a) computer languages - $\mathrm{C \#}, \mathrm{C}++$, JAVA;

(b) script languages - Perl, VB-Script;

(c) web markup languages - Hyper text markup language, Dynamic HTML, XML;

(d) server-based programming tool - Active server pages (ASP), JAVA Servlet; (e) distributed object modelling methods; distributed component object model, remote method invocation (RMI), common object request broker architecture (COBRA), .NET etc.;

(f) commercial software packages - STEP, CAD.

The current research work shows that web technology is being used to handle information systems concerned with syntactic and structural heterogeneity. However growing access to heterogeneous and independent data repositories requires the treatment of structure as well as semantics of the data stored in those repositories. In order to handle the interoperability challenges of the future manufacturing plant, it is necessary to make knowledge explicit and machine-interpretable. For improved understanding of disparate knowledge in a distributed environment, it is necessary to declare semantics of information in a machine readable way. Through machine-based reasoning and inference, entities can gain understanding about others skills, goals, and interaction models and therefore interact and collaborate more easily.

\subsection{Role of semantic web in manufacturing}

In current markets, firms often align their plans, processes, and information systems to integrate services and facilities that initially were developed independently. However, collaborating partners often use different terminologies to describe the same meaning or the same terminology is associated with different meaning. Such lack of consistent semantic descriptions about the meaning of contents in a particular domain has hampered the interoperability and sharability of knowledge and the development of collaborative firms. Thus, the nextgeneration manufacturing systems need sets of interconnected data and semantic models to communicate and exchange their knowledge [16]. The current research direction is focused on developing semantic agreements among collaborating partners for fixing standardized meanings and relations of terminologies used. Semantic web is a vision for extending current web technology in which information is annexed with a well-defined meaning that enhances the interoperability of computers and people. It plays a crucial role in automating the functions performed by different manufacturing applications. It is basically an extension to the existing web by providing a framework that gives meaning to data and applications for automatic processing.

The semantic web relies heavily on ontologies to structure data for comprehensive and transportable machine understanding. Ontologies are an integral part of semantic web in facilitating knowledge sharing and reuse. Initially ontology was confined to the philosophical sphere, but currently they are 
widespread in different research fields. In the field of manufacturing, ontologies are utilized for knowledge representation, knowledge engineering, information modelling, database development and integration, information retrieval and extraction, knowledge management and mining, and agent-based system development. They are used to share technical and business information throughout the firm or even in extended or virtual manufacturing enterprises. An ontology basically contains concepts, concept taxonomies, and relationships to support information exchange and knowledge sharing. It is used as a mechanism for expressing and sharing enterprise knowledge to define common vocabularies and to support intelligent queries over heterogeneous databases.

The role of ontologies in manufacturing has become prominent in recent years. A substantial amount of research has been performed on utilizing ontologies for modelling manufacturing activities. Among the wide spectrum of approaches which differ in complexity and scale, four groups of approaches can be distinguished for manufacturing ontologies, i.e. top level, domain, task, and application level ontologies. Top-level ontologies are used to represent the building blocks for a particular domain. Domain and task level ontologies are used to represent vocabulary related to certain domains or tasks respectively. Finally, application level ontologies are used to describe concepts depending on a particular domain or task. The work done in each level is now described below.

\subsubsection{Top level ontologies}

These ontologies are the first step towards knowledge representation for any domain. Zhou and Kuntz [43], provide the foundation work required for ontology driven excellent manufacturing. Here, the authors have developed a top level ontology for representing the fundamental terms of manufacturing, i.e. product, organization, activity, actor, facility, method, and value. The framework consists of generic entities of any manufacturing domain for providing products and services using material flow, information flow, and cost flow. Similarly, Dori and Shpitalni [44] laid a foundation for an ontology of the generic life cycle of a product that includes the entire life cycle of the product, from its design to the end of its life. In particular, they have utilized the object-process methodology (OPM) for modelling the entire product life cycle in a single unified and consistent view.

Gialelis et al. [4] present an ontological model for applications and systems that participate in collaborative processes under the manufacturing domain. The authors have proposed an architecture that combines web services, ontologies, and work flows for efficiently carrying out the integration process under a collaborative environment. Here the integration is carried out by describing the enterprise processes by means of work flows and by using web services as a channel of communication within an enterprise. Similarly, Suárez et al. [45], prepared a top-level ontology for a distributed supervision system used in process industries. Here the SFDD ontology for supervision, fault detection, and diagnosis is developed by using the terms, i.e. variables, system behaviour, supervisory task, models, and system properties. Lin and Harding [46] provide a top level description for manufacturing system engineering knowledge representation, called the MSE ontology. The MSE ontology model is used to facilitate communication and information exchange among multidisciplinary teams coming together to support collaborative work.

\subsubsection{Domain level ontologies}

As mentioned earlier, various top-level manufacturing ontologies have been proposed in literature published by several organizations. The intention of these models is to define a neutral representation for a distributed manufacturing environment. Although such representations can be used for entire manufacturing environments, they are not suitable for handling complex interactions among individual processes. To handle such complex process integration and coordination, domain ontologies have been developed to model particular domains of manufacturing. Kim and Chung [47] modelled the design and manufacturing processes of various companies and further used these ontological models for collaboration. Their framework was called the WSCPC (web service-based collaborative product commerce) and was proposed to facilitate design and manufacturing process integration and collaboration using web services technology. The ontologies developed for each domain enabled collaborative partners to understand each other's decisions and behaviours and thus support complex interactions.

Nanda et al. [48] used ontology for efficiently and effectively capturing and representing the knowledge existing in product development repositories. An ontology-based framework was introduced to collect, store, retrieve, reuse, and represent relevant information from existing designs to improve the design of product families. Lee et al. [49] developed a conceptual framework for managing the product design information for designing products with better environmental performance from a system perspective. The sharing of information among product designers and stakeholders is managed and facilitated with the development of a relevant ontology for the entire framework. Yang et al. [50] proposed an ontology modelling technique for solving the 
problem of semantic interoperability in collaborative product development processes. A product development process comprises a set of development activities, connection relations, and dependencies between these activities, information flows, etc. In this paper, Yang et al. used domain ontologies for capturing the semantics of a certain domain and further utilized them for the integration of product development processes. The methodology proposed in their paper is a combination of the service-oriented paradigm, interoperability standards, ontology engineering, and web services to facilitate the integration of product development processes.

Delamer and Lastra [51] presented an ontology for the manufacturing domain of assembly. It consists of a process taxonomy (hierarchical classification of manufacturing processes), equipment taxonomy (list of industrial devices and machines), and product taxonomy (information about parts and sub-parts of products). The individual ontologies are stored in different information repositories for facilitating the maintenance and further development of represented knowledge.

\subsubsection{Task level}

A manufacturing domain consists of numerous entities performing their respective operations. Task level ontologies are used to model these entities and support interaction and interoperability among them. Gialelis et al. [4] modelled the systems and applications that participate in the industrial environment from shop floor to boardroom. As a test case they presented an ontology model for a procurement process carried out by suppliers for ordering raw materials, supplies, spare parts, tools, equipment, and other required materials. Functional design is a key step in the product design process. Zhang et al. [52] developed an ontology-based scheme for collaborative functional modelling in design for semantic web applications. Their ontological model serves as a basis for organizing knowledge in a more structured manner.

Current global trends continuously force manufacturing firms into planning new systems or retrofitting existing ones. Such reconfiguration is a fundamental problem in manufacturing systems, which require rapid change and cost effectiveness. According to Obitko and Marik [53] implementation of ontologies in the area of multi-agent manufacturing systems is a key strategic issue for successful development of future production systems. Generally, task level ontologies are implemented in the field of multi-agent systems to model the tasks of various agent systems. Pouchard and Rana [39] discussed the role of ontologies for interoperability and exchange of messages between agents. Here the authors highlighted the use of ontology for interoperating different integration scenarios and showed manufacturing process integration as a case study. Merdan et al. [54] implemented the concept of ontology-based knowledge management systems in connection with software agents to achieve reconfiguration. Their ontology-based system was used as a translator for enhancing the communication among software agents available in a manufacturing domain. Further Merdan et al. [37] presented a knowledge-intensive multi-agent architecture that enabled ontology-based communication and cooperation among a set of autonomous and heterogeneous agents.

\subsubsection{Application level}

A manufacturing life cycle comprises several applications, e.g. process planning, process modelling, scheduling, workflow, and simulation. These applications do not usually interoperate, although the output data and process information of one process may be input to another. Application level ontologies are used to map them for their structured operation and interaction. Xin [55] used ontology for performing semantic-based information interoperation in different application domains of a supply chain system. A supply chain basically integrates distributed and heterogeneous departments, i.e. suppliers, purchasers, storage, manufacturing, sales person, etc. Each unit of a supply chain uses different terminologies to represent and reason about their product and process. Therefore, application ontologies have been used to preserve semantics of respective departments and semantic mediator mapping enabled support interoperability among applications. Mönch and Stehli [56] developed an application ontology for hierarchically organized production control systems in a semi-conductor manufacturing system. This is a complex system that can be decomposed into a set of interconnected subsystems. An ontological model developed to support interaction among different activities should consist of domain as well as task-related parts.

\subsection{Enterprise ontologies}

From the above descriptions, it is evident that there is a plethora of literature related to the implementation of ontology in the domain of manufacturing. But there are only a handful of efforts that have attempted to model manufacturing-related information in a formal ontology. However, other work has been done to make this modelling process easier or has modified it for a particular purpose. Some important ontologies developed by the artificial intelligence community and language engineering community are provided in Table 2 [57]. From the table it is evident that only a few ontologies have been developed specifically for the manufacturing community. 
Table 2 Summary of ontologies present in literature (extended from [57])

\begin{tabular}{|c|c|c|c|c|c|}
\hline S. No. & Name & Year & Developed by & Domain & Purpose \\
\hline 1 & $\begin{array}{l}\text { ANSI ad hoc committee } \\
\text { on ontology standards }\end{array}$ & 1998 & $\begin{array}{l}\text { ANSI ad hoc Group } \\
\text { on ontology } \\
\text { standards }\end{array}$ & Generic & $\begin{array}{l}\text { To merge existing ontologies and } \\
\text { develop an upper level ontology }\end{array}$ \\
\hline 2 & Сус & 1998 & Cycorp. Inc. & Generic & $\begin{array}{l}\text { Developed on the basis of micro } \\
\text { theory } \\
\text { Captures the knowledge and } \\
\text { reasoning required for some } \\
\text { particular domain }\end{array}$ \\
\hline 3 & Enterprise ontology & 1998 & Enterprise project & $\begin{array}{l}\text { Enterprise and } \\
\text { business modelling }\end{array}$ & $\begin{array}{l}\text { Collection of terms relevant to } \\
\text { business enterprise }\end{array}$ \\
\hline 4 & LOOM & 1998 & $\begin{array}{l}\text { University of } \\
\text { Southern California }\end{array}$ & Generic & $\begin{array}{l}\text { Language and environment } \\
\text { suitable for applications that use } \\
\text { ontology }\end{array}$ \\
\hline 5 & Milkrokosmos & 1995 & $\begin{array}{l}\text { Mahesh and } \\
\text { Nirenburg, New } \\
\text { Mexico State } \\
\text { University }\end{array}$ & $\begin{array}{l}\text { Knowledge-based } \\
\text { translation for } \\
\text { natural language }\end{array}$ & $\begin{array}{l}\text { A methodology for representing and } \\
\text { translating natural language from } \\
\text { one language to other }\end{array}$ \\
\hline 6 & Ontolingua & 1997 & Stanford University & Generic & $\begin{array}{l}\text { Web based interface for creating, } \\
\text { browsing and reusing ontologies }\end{array}$ \\
\hline 7 & TOVE & 1998 & TOVE project & Enterprise integration & $\begin{array}{l}\text { Integrated enterprise model based } \\
\text { on interaction of core ontologies, } \\
\text { derivative ontologies and } \\
\text { enterprise ontologies }\end{array}$ \\
\hline 8 & STEP & 1994 & ISO-10303 & Product data & $\begin{array}{l}\text { Ontology used for } \\
\text { exchange of product data } \\
\text { throughout their life cycle }\end{array}$ \\
\hline 9 & PSL & 1999 & NIST & $\begin{array}{l}\text { Ontology for } \\
\text { describing } \\
\text { manufacturing, } \\
\text { engineering and } \\
\text { business process }\end{array}$ & $\begin{array}{l}\text { Neutral representation for } \\
\text { manufacturing processes to } \\
\text { support automated reasoning }\end{array}$ \\
\hline 11 & XLANG & 2001 & Microsoft Corporation & Generic & $\begin{array}{l}\text { Provides both the model of an } \\
\text { orchestration of services as well as } \\
\text { collaboration contracts between } \\
\text { orchestrations }[\mathbf{5 8}]\end{array}$ \\
\hline 12 & BPML & 2001 & $\begin{array}{l}\text { Business Process } \\
\text { Management Initiative }\end{array}$ & Business process & $\begin{array}{l}\text { Meta-language for modelling } \\
\text { business processes }\end{array}$ \\
\hline 13 & Web-PDDL & 2002 & $\begin{array}{l}\text { D. McDermott and } \\
\text { D. Dou }\end{array}$ & Generic & $\begin{array}{l}\text { Web-Planning Domain Definition } \\
\text { Language used to represent } \\
\text { ontologies, datasets and queries [59] }\end{array}$ \\
\hline 14 & MSE & 2004 & Lin et al. & $\begin{array}{l}\text { Extended enterprise } \\
\text { integration }\end{array}$ & $\begin{array}{l}\text { A taxonomy of manufacturing terms } \\
\text { and concepts to make design } \\
\text { knowledge effectively accessible } \\
\text { across extended enterprises [46] }\end{array}$ \\
\hline
\end{tabular}

However several other manufacturing or enterprise information models are also present in literature, such as CIMOSA, MOSES, MISSION, FDM [5, 17, 46, 60] that describe the structure and relationships of data and information elements within manufacturing enterprise information systems. However, these models have been developed for intra-enterprise integration [60]. Some generic ontology models such as TOronto Virtual Enterprise (TOVE), GRAI, GERAM, ARIS, Enterprise ontology, PSL, Electronic business using eXtensible Markup Language (ebXML), Business
Process Modelling language (BPML), etc. have been proposed for enterprise integration $[\mathbf{5 7}, \mathbf{6 1}]$.

Information models for manufacturing systems are mainly classified into two categories, i.e. the ones that emphasize modelling of activities of manufacturing systems and the ones that are concerned with the actual knowledge sharing procedures [26, 57]. The former category of information models put their emphasis on representation of terminologies used specifically in the manufacturing domain. CIM-OSA, STEP model, and Process specification 
language (PSL) are some of the ontological models belonging to this category. CIM-OSA (computer integrated manufacturing open system architecture) is a methodology developed at Purdue laboratory for appropriate integration of operations by means of efficient information exchange within the enterprise. The STEP (Standard for the Exchange of Product Data) model is developed to support the exchange of information by aiming to create a standard language for exchanging manufacturing product data. Although some work has been done to develop STEP models for manufacturing processes, it is limited to modelling the product structure information such as, geometric, dimensions, and tolerance. Subsequently, the PSL was developed as a standard language that provides unambiguous definitions for manufacturingrelated concepts and a mechanism to support translation of definitions among applications. The PSL approach was developed at NIST (National Institute of Standards and Technology, 1999) as a common exchange language that enables distributed collaboration in manufacturing. Schlenoff et al. [61] have focused on PSL development to identify, formally define, and structure the semantic concepts of discrete manufacturing process information. Pouchard and Rana [39] also utilized PSL for resolving the problem of synonymy and semantic plurality faced during the interoperability of former applications. The information models belonging to this category are focused on particular areas of manufacturing and therefore do not cover all the terminology aspects and needs that are necessary for knowledge sharing within enterprises.

The second category of ontology models is concerned with the representation of knowledge within intra- or inter-enterprise systems. The models belonging to this category are Enterprise Ontology, TOVE, BPML, ebXML, and MSE. The Enterprise Ontology was developed under the Enterprise project to provide a collection of terms and definitions relevant to business enterprises [62]. The Enterprise Ontology was not developed for a specific type of enterprise, but as a generic model oriented towards business and organizations rather than towards specific domains. Similarly, TOVE was developed to support enterprise integration with minimum ambiguity and maximum understanding and precision in communication [63]. TOVE provides a generic and reusable ontology for modelling enterprises. The philosophy behind TOVE is that enterprises are action oriented and thus it is necessary to model those actions when developing enterprise models. It is basically the group of ontologies comprising three different categories of ontologies, i.e. core ontologies for product, services, activity, and resources; derivative ontologies for transportation, inventory, quality, product design, scheduling, product requirements, and information resources; and enterprise ontology for enterprise design, project handling, material flow, and business process.

BPML represents a new family of process definition languages intended for expressing abstract and executable processes that address all aspects of enterprise business processes [64]. It provides an abstract execution model for collaborative and transactional business processes based on the concept of a transactional finite state machine. ebXML is a family of XML standards sponsored by OASIS and UN/CEFAT [65]. It enables enterprises of any size and in any geographical location to conduct business over the internet. Recently, the MSE model was proposed to provide common understanding of manufacturing related terms to enhance semantic interoperability and reuse of knowledge resources within globally extended manufacturing teams [46].

The former descriptions of semantic web and ontology clearly show that there are an increasing number of efforts to develop formal representations of manufacturing terminology and concepts. The aim is to develop a common infrastructure for reusing information and integrating disparate applications within the manufacturing community. However, integration is only possible if there is common language which can be shared among applications for representing the terms used by firms [66]. Besides ontology, the other basic blocks for creating semantically rich environments are standardized languages for ontology.

Several ontology languages have been developed during the last few years and have been used in the context of the semantic web. These ontology representation languages are either logic based, frame based, or web based. A comparison between all the existing ontology languages is provided in references [66] and [67]. The languages are the extended versions of XML syntax that provide greater machine interpretability and semantic interoperability. Some of them are ontology exchange language (XOL), Simple HTML Ontology extension (SHOE), and Ontology markup language (OML), which are the primary extensions of the XML syntax. However, other popular ones are RDF and RDF Schema (RDFS) developed by world wide web consortium (W3C). These allow the specification of the semantics of data based on XML in a standardized and interoperable manner. Although they explicitly represent services, processes, and business models, they do not provide mechanisms for defining the relationships between attributes and resources. To improve the features of RDF and RDF-S, DAML-ONT and OIL have been introduced with logical layers and rules as extension. DAML-OIL is an evolution of DAML-ONT and is compatible with OIL primitives. All web ontology languages present in the current literature are shown in Fig. 3. 


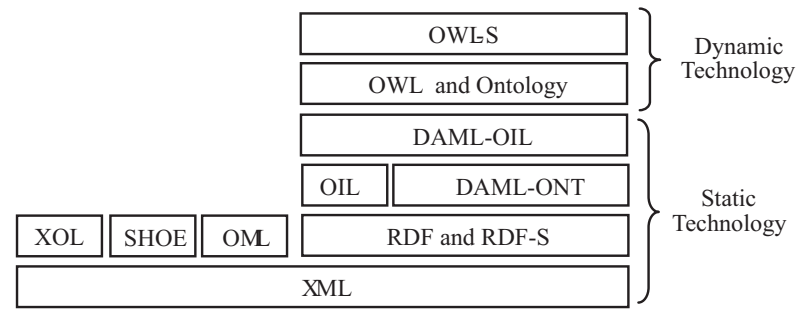

Fig. 3 Different ontology languages proposed in literature

The web ontology language OWL is the most expressive language for specifying, publishing, and sharing ontologies. It facilitates greater machine interpretability of web content than is supported by $\mathrm{XML}, \mathrm{RDF}$, or any other language proposed in literature. It is the only standard web ontology language that provides formal semantics along with additional vocabulary. It is derived from DAML-OIL language by the W3C Web Ontology Working Group. It is well suited for knowledge representation as it includes axioms and definitions for facilitating machine interpretability. OWL mainly comes in three sublanguages: OWL Lite, OWL DL, and OWL full, which are intended to be layered according to their increasing expressiveness. OWL-S is an extended OWL ontology for modelling of semantic web services. However, according to references $[40,68]$ and [69] the expressiveness of OWL alone is not enough for the specification of web services. To overcome this limitation, OWL-S has been developed for combining different notations and semantics with OWL and it is therefore an OWL ontology that specifies the concept of web services.

Along with the language for describing information and interaction semantics, it is necessary to build up a platform for sharing and exchanging information. The traditional web-based infrastructure utilizes web services as a mechanism for sharing and exchanging the multimedia data and information. A web service provides an interface to describe the structure of documents in an extensible fashion to create instances of documents, manipulate them, link them, and validate them. Continuous research efforts are being made to bring semantics into web services and enable software to understand the content and manipulate them in a meaningful and useful way. A semantic web service is a framework that consists of semantic markup for web services to make information machine understandable and use-apparent. These services can be described by an OWL-S ontology automatically to discover, invoke, compose, and monitor the associated processes.

\subsection{Semantic web services in manufacturing}

The research work in the field of semantic web services implemented in manufacturing systems has gained attention in the last few years. Terziyan and Kononenko [14], analyse the current stage of web services and semantic web and later discuss the technical issues and challenges faced during industrial implementation of semantic web services in industries. They have developed a framework based on the semantic web and web technology to provide solutions for building a large-scale industrial maintenance network. Kulvatunyou and Ivezic [70] explored the potential use of semantic web in the context of manufacturing web services. Kim and Chung [47] used an OWL-S ontology for representing design and manufacturing activities. The present authors have developed a framework entitled WSCPC to facilitate design and manufacturing processes integration and coordination. This framework was developed to enable manufacturing firms to publish their capabilities and identify potential manufacturing partners at the same time.

Yang et al. [71] developed a semantic web-servicesbased architecture that enables automated integration of manufacturing systems and services. The key to the semantic web-services-based approach proposed in their paper is to develop an integrated business process model for an integrated enterprise. The crucial components of this framework are standardized web ontology language (OWL) and semantic markup for web services (OWL-S). Delamer and Lasta [20] used the OWL-S semantic web service ontology for developing a protocol used for the discovery of services in an industrial environment. Delamer and Lastra [51] utilized semantic web services for modelling industrial processes and systems required for handling high product mix and frequent new product introduction. Chen and Zhang [72] also utilized semantic web services for the effective operation of a collaborative virtual enterprise. A semantic rich integration architecture based on a forward chaining algorithm was developed to realize dynamic integration among enterprises. The forward chaining engine was used to find new candidates for integration based on the current set of inputs and outputs. Recently, Lastra and Delamer [73] provided a brief insight into the challenges faced during the implementation of semantic web services in factory automation. In this paper, a methodology for achieving a self-reconfigurable and autonomous production system was developed using semantic web services. The methodology is applicable to a system that equally may or may not have previous knowledge of the other types of element such as manufacturing system integration, factory and enterprise integration, planning and scheduling, intelligent machines, etc.

The next section provides a discussion on the prime areas of manufacturing that can incorporate these tools to enhance their competitive and cooperative positions in the market. 


\section{EVOLUTION OF INTELLIGENCE IN MANUFACTURING}

The competitive and frequently changing environment has made it essential for manufacturing firms to enhance productivity, shorten product life cycle, increase product customization, and improve responsiveness to remain viable in the market [74]. To achieve these seemingly conflicting objectives, manufacturing enterprises are readily employing intelligence to provide them with a consistent route towards continuous improvement. Intelligence is being employed for building insight, foresight, and knowledge about their operations and trends that effectively manage their present and shape their future [75]. Intelligence in manufacturing is something that a firm needs in order to improve their capabilities and proactively address the frequent changes in market and constant evolution in technology. Manufacturing intelligence facilitates the effective management of the present and shaping of the future.

A manufacturing factory environment is a balanced system composed of numerous autonomous entities interrelated for producing usable products and services. All these entities including planning, design, procurement, production, inventory, marketing, distribution, sales, and management collaborate to address the competitive issues of the manufacturing enterprise. The primary challenge for a collaborative manufacturing network is the effective exchange of accurate and meaningful information. Muata et al. [76], have identified five fundamental characteristics for the success of collaborative firms, i.e. effective coordination of industrial activities, highly interactive systems, external forces for business environment, internal as well as external interaction, effective control mechanisms for product / process design and manufacture.

The main input and output for a whole range of manufacturing activities is information (in various forms). Therefore, its availability, ability to exchange it seamlessly and process it quickly are major factors for making decisions about operating strategies. However, the growing complexity of manufacturing information and the increasing amount of knowledge and information required by a wide variety of users has made it increasingly difficult to share and exchange knowledge efficiently and effectively. Moreover, global manufacturing environments are very complex and produce difficulties in communicating and understanding shared or exchanged knowledge across the world due to differences and vagueness in languages, organizational background, customs, and habits. The difficulties in resource sharing and collaboration are also caused by diversity in different kinds of manufacturing as follows:

(a) differences in the workflow cause possible difficulties in coordination of the knowledge transfer; (b) differences in terms create misunderstandings and lead to a different interpretation in the knowledge exchange process;

(c) differences in organizational cultures cause difficulties in accessing the complete knowledge of the firm;

(d) difficulties in structuring and classifying the company's knowledge causes misunderstanding in sharing of information.

Various tools and techniques have been proposed in literature to reduce diversity. For example, expert systems are proposed for decision making, standards are used for information sharing, web technologies are available for data publishing and access, ontologies are used for knowledge management, semantic web is used for understanding and interpreting the terms, web services are provided for accessing the knowledge on the network. This section presents the characteristics of applications of ontologies and semantic web services in the main manufacturing domains.

\subsection{Enterprise management}

An enterprise is a management system comprising all facets of business, including purchasing, marketing, design, production, maintenance, and distribution, etc. Generally, an enterprise system is classified into a hierarchical model comprising three different layers, i. e. enterprise layer, plant layer, and shop-floor layer. Each layer consists of a number of structured operations concerned with data exchange and function calls. It is basically a management system that arranges its process, resources, and strategies as per their business objectives. The heterogeneous and non-holistic view of an enterprise complicates the unification of enterprises. The advent of communication infrastructures based on enterprise intranet and internet has made it possible to unify the former three layers of enterprise management systems. The primary requirement for an enterprise layer is to determine a sequence of diverse applications residing in the different layers of the enterprise model. Workflows are often considered to be the key technology for specifying an enterprise process as a sequence of diverse applications and processes. Various standards are present in literature for workflow specification, these include Work flow Reference model, SWAP (Simple Workflow Access Protocol), Wf-XML (Work flow extensive markup language), to associate diverse applications and services of a system [77].

Due to the ubiquity of internet in recent industrial environments, the workflow standards are generally interfaced with different communication infrastructures including web services technology. Web services allow different pieces of software or machines to communicate with each other in a standardized messaging format. Therefore, each layer 
of the enterprise system can be implemented with a common standard interface for better communication and optimal utilization. Such integration and collaboration between different layers in the enterprise model enhances the quality of products and services and provides better global competitiveness in the market place.

With the advent of internet and economic globalization, enterprises increasingly need to cooperate with each other and develop extended enterprises capable of handling large projects. Virtual enterprise, supply chain, dynamic alliance, and industrial alliance can all be considered as distinguished forms of extended enterprise. An extended enterprise comprises numerous interconnected enterprises with different organizational background, languages, customs, and habits. Compared with a single enterprise, knowledge sharing and communication among such multidisciplinary teams is a notoriously challenging and complex problem. The two common types of problem that occur in sharing and exchange of information are semantic (same term applied to different concepts) and syntactic problems (different terms used for the same entity). A solution to this problem is to model a taxonomy of terms and concepts prevailing in the domain of the enterprise [46]. An approach generally used for developing enterprise knowledge management is to develop an ontology with well-defined terminology accepted by all participating firms. For example, an enterprise ontology is shown in Fig. 4 to capture the enterprise competence in computer understandable form. The aim of an enterprise ontology model is to define semantics for the domain terminology in an easy to understand way. Such an ontology model is similar to a dictionary, taxonomy, or glossary, but with structures and formalisms that enable computers to process its contents. An enterprise ontology may consist of the following:

(a) terms used to define the basic entities and relationships of enterprise;

(b) terms for processes and planning;

(c) terms for resources;

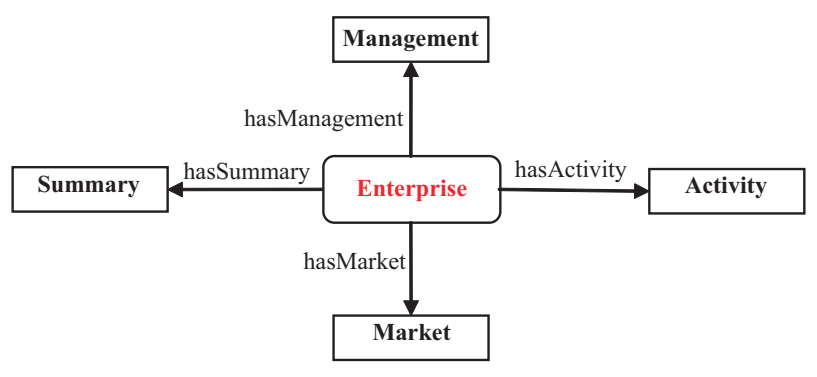

Fig. 4 Top level enterprise ontology (d) terms related to the structure of organization;

(e) terms related to high level planning of enterprise;

(f) terms related to marketing and selling.

\subsection{Manufacturing strategies}

The current manufacturing environment is characterized by frequently changing market demands, continuously emerging new technologies, and, above all, global competition. Considering the present market scenario, manufacturing strategies must be able to support global competitiveness, innovation, new product development, and strong market responsiveness. Similar to the hierarchical models described for enterprise management, manufacturing strategies are also classified into layers, i.e. enterprise, factory, station, and cells. Lower level strategies are responsible for individual processes whereas the higher level of strategies are responsible for combining the sequence of lower-level strategies. The ultimate goal of such manufacturing strategies is to have seamless integration for conveniently and effectively using each other's functionality.

An industrial environment comprises a great number of systems and applications having their own local knowledge and disparate tools, which are often distributed in different geographic locations. Therefore, efficient management of this distributed knowledge is required to enable devices to interact and collaborate intensively. Various standardization approaches have been proposed to overcome the challenges of integrating heterogeneous factory components and improving their interoperability. But the inflexibility of standard-based systems to assimilate new types of component and integrate them with other existing components has created problems in the expansion of standardization. To overcome this interoperability issue, the concept of ontology and semantic web services has been introduced for developing intelligent factory environments. Figure 5 gives a bird's eye view of an interoperating manufacturing execution system (MES) by using ontologies and semantic web services. The individual MESs can develop local ontologies and subsequently map, merge or compare local ontologies to develop global ontologies for interoperability.

\subsection{Product design and planning}

Product design and planning are considered to be the core activities for industrial companies. Manufacturing is the process of transforming customer needs into realized product through a complex set of design and planning activities. Among all the functions of a manufacturing enterprise, design and planning are considered to be the most important and critical factors for its future survival. As discussed 


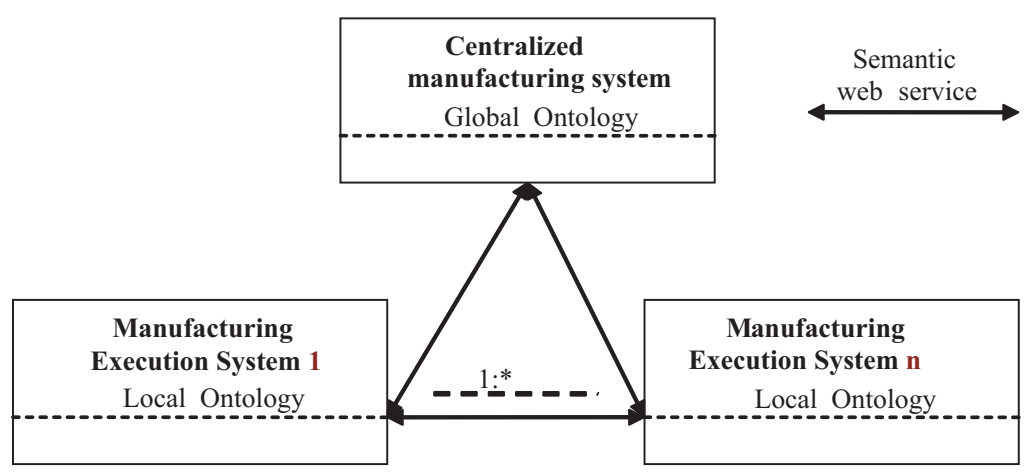

Fig. 5 Illustrative scenario for the use of ontologies and semantic web services in manufacturing strategies

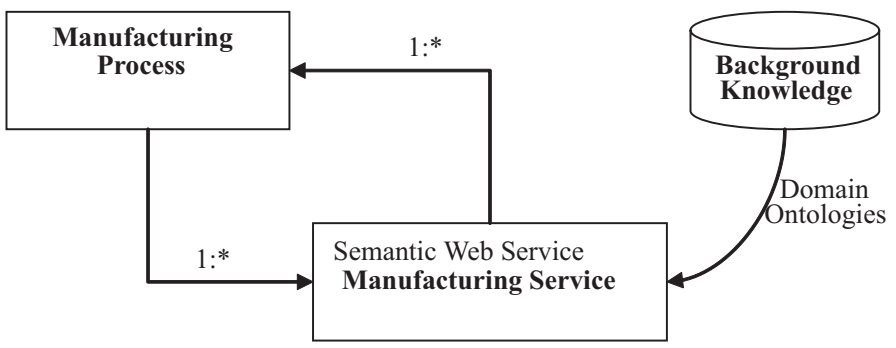

Fig. 6 Illustrative scenario for use of semantic web and ontologies in manufacturing processes

in True and Izzi [78], 70 per cent of product cost is determined during its design and planning phase. Moreover, it has a major influence on the other functions as well as on competitiveness of an enterprise. Thus, it is an essential requirement for a firm that the information used for design and planning must be used and utilized efficiently and effectively. Initially, networking technologies were used to facilitate the information sharing in product design and planning process. The capabilities and benefits of computing utilized to meet business goals of profitability and innovation are as follows [79]:

(a) speeding up the information flow and disseminating it more widely;

(b) networking technologies to enhance decision making and increase connectivity and interoperability among information sources.

Traditionally, networking technology uses taxonomies or glossaries for capturing and storing knowledge in a form that facilitates its reuse, sharability, and extendibility. However, taxonomies were not able to address the basic requirements of design and planning domains. Product design and planning consist of various autonomous entities, i.e. humans or machines, to communicate information and knowledge using heterogeneous sources. Taxonomies, i.e. the knowledge management process, were not able to circumscribe the meaning and logical properties of the terms as precisely as possi- ble. Therefore, taxonomies were replaced by ontologies for capturing and storing the domain knowledge. Ontologies have been developed to support the exchange of meaningful information across autonomous entities that can organize and use information heterogeneously. An ontology is a hierarchically structured set of terms for describing a domain that can be used as a skeletal foundation for a knowledge base. They are very useful for knowledge reuse and knowledge sharing. The ontology model developed for design and planning data are shared using semantic enabled web services. A generic scenario for the use of semantic web and ontologies and semantic web in manufacturing processes is illustrated in Fig. 6. In this illustration, different manufacturing processes utilize multiple manufacturing services (semantic web services) supported by the background knowledge stored as domain ontologies.

\subsection{Marketing and support services}

Current market trends indicate that demand for highly customized products with lower cost and shorter lead time is increasing at an exponential rate. To remain viable in such competitive markets, it is imperative for firms to improve their productivity, responsiveness, and flexibility by reducing the costs of system deployment, maintenance, and recycling. Manufacturing firms are trying to meet these requirements by integrating customers in their 


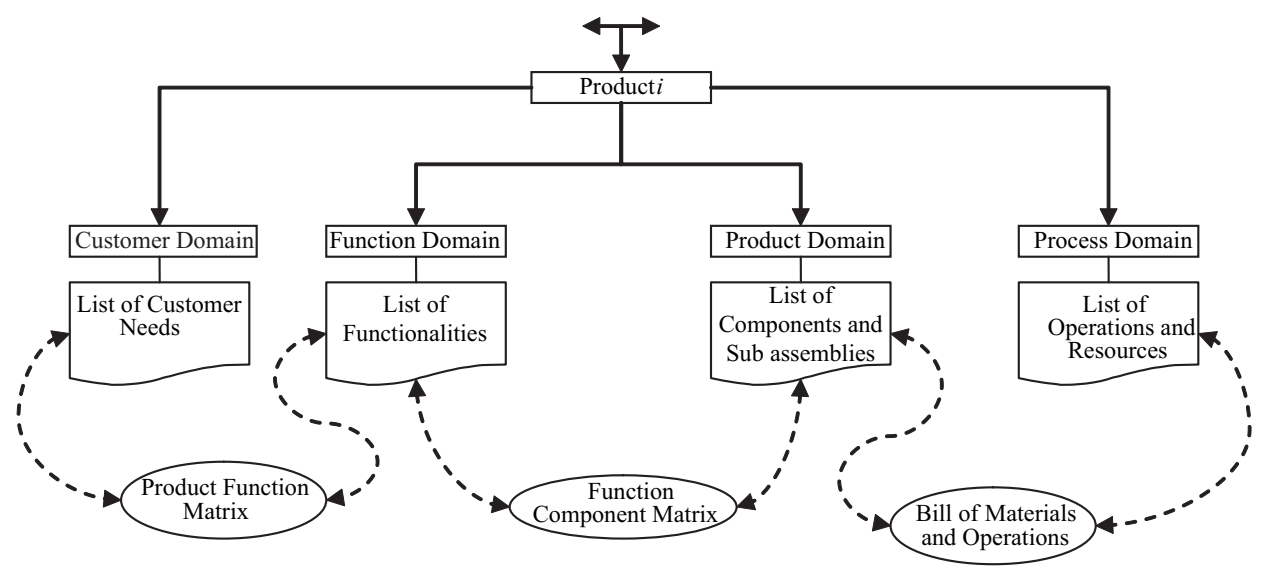

Fig. 7 Top-level ontology for product description

strategies and developing customer-oriented production. Customer involvement plays an important role in new product development. According to Lagrosen $[\mathbf{8 0}]$, customer involvement occurs in different phases of product development process, e.g. idea stage, development stage, and prediction stage. The internet is viewed as a key enabler to improve customer involvement in earlier stages of the product development process. It has provided new channels for collecting customer demands, promoting products, delivering services, and making sales.

With the advent of computers and networking technology, customers are able to obtain information more quickly and easily. Thus, manufacturing firms are facing a challenge to deliver a high variety of customized products at lower cost and in shorter lead times. The direct consequence of this increased number of variants is large amounts of product data and information. Handling this massive amount of information is often difficult, if not impossible. The traditional approach for handling this information is to develop a generic representation scheme reflecting different variants and relationships between them. Although this approach of handling generic structures has been well recognized as a tool for variety management, problems arise when different terminologies are used by different engineers. Consequently, differences in terminology result in large amounts of redundant information. In order to overcome this drawback, generic ontology models are developed for data management. Figure 7 shows an example ontology to enhance the manageability of large amounts of product data and ultimately influence the basic organization's functions such as customer order processing, variety management, production planning, material and capacity planning, etc. $[\mathbf{8 1}]$.

The next section describes a real-life implementation of an ontology and semantic web service to support the management of a wide variety of information resources.

\section{ONTOLOGY FOR INFORMATION RESOURCES}

In recent years there has been a significant growth in the number of information resources in the area of manufacturing. The previous section clearly shows that the application of semantic web and ontology in manufacturing is increasing rapidly in several key areas. An ontology may be assumed to be a conceptual system, which underlies a particular knowledge base and is used to develop a suitable formal structure for that knowledge base. Ontology-based knowledge representation is a powerful scheme to model concepts and relationships that allow the design, sharing, and reuse of knowledge in a disciplined way. It captures the domain knowledge and establishes common vocabularies that can be understood by systems as well as humans.

In this paper, an ontology model for the knowledge base of information resources is developed to illustrate the real-life implementation of ontology and semantic web. The information resource ontology model is used to capture, design, and organize the reference materials in an explicit manner. It is proposed to enhance the manageability of large amounts of information resources, including books, periodicals, reports, patents, standards, web pages, blogs, etc. [82]. This model can also help academics or industrialists to capture their reference material in a unified and explicit manner.

The first step required in building an ontology is to identify the key concepts and relationships existing in a domain. This is essential for defining the semantic definitions of concepts and relationships. The information resource ontology model captures the information about reference materials under seven domains, i.e. academic (thesis, tutorial), book, industrial (minute and report), periodical (conference proceeding, journal, magazine, and newspaper), service (alerting service, search tools, open, and closed source software), standards and patents, and unpublished materials (blog, webpage, and wiki). 


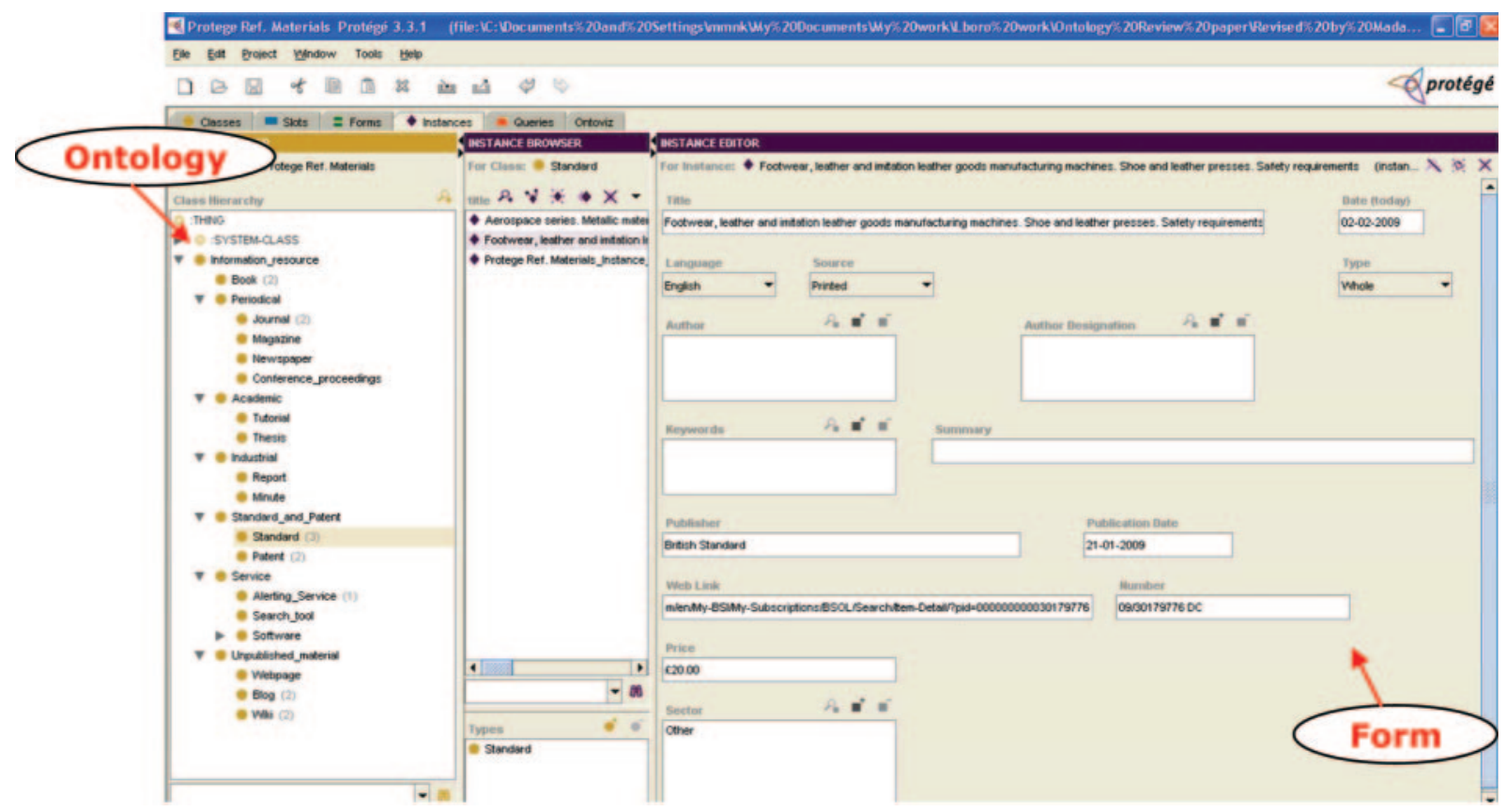

Fig. 8 A screen shot of the resource information ontology and form

The top-level ontology model illustrating these key classes and their properties is shown in the Appendix. It is evident from the figure shown in Appendix A that all the classes are associated by means of a relationship and the properties add information to that class. The information of the reference materials will be used to populate this ontology and develop a knowledge base.

Protégé-3.3.1 has been used to develop the information resource ontology model and subsequently to build a knowledge base. Protégé has been used as it allows the user to construct a domain ontology having concepts, features, and feature relationships in a lucid manner. Moreover, this integrated software tool enables an open knowledge base connectivity platform to be developed for accessing the knowledge base. Protégé plug-ins are also present in this software for various applications concerned with the modelling, creation, and edition of ontologies and ontologies instances. Onto-viz is one of the Protégé plug-ins and has been used here to provide the graphical representation of the ontology. This plug-in has also been used to develop the graphical model of the proposed ontology model that is shown in the Appendix.

The ontology model for information resources proposed in the present paper can be used to store the relevant reference materials. A screen shot of the ontology for reference materials and the form used for populating the ontology with information (e.g. standards) is shown in Fig. 8. The populated database developed in Protégé can later be used for searching the information by using their names, attributes, etc.
For example, a user might extract the journal papers stored in the database, list of wikis appropriate to their discipline area, a list of relevant magazines and newspapers, or details of any other stored information resources, simply by using particular phrases or keywords, etc. An example of querying the populated knowledge base is shown in Fig. 9. The reference materials in manufacturing sector and in English language are searched in this figure. The ontology model that was developed during this research can be obtained on the web and can be used to develop a personal knowledge base of reference materials. The web link is: http://www-staff.lboro.ac.uk/ mmnk/ ontology/Information_resource.html. Academic researchers and industrialists can import this ontology model into their Protégé software and use it as it is or modify it according to their requirements.

An ontology is generally encoded in some formal language to express the domain concepts in a manner that computers can understand and manipulate easily. Protégé uses OWL format (Web Ontology language) to express the ontology in a unique form that facilitates its reuse and sharing. The OWL format for the Information Resource ontology imported from protégé is available at: http://www-staff.lboro.ac.uk/ $\sim \mathrm{mmnk} /$ ontology/reference.owl.

\section{CONCLUDING REMARKS}

The current trends in manufacturing impose an increasing demand for autonomous collaboration, reconfigurability, and heterogeneous system 


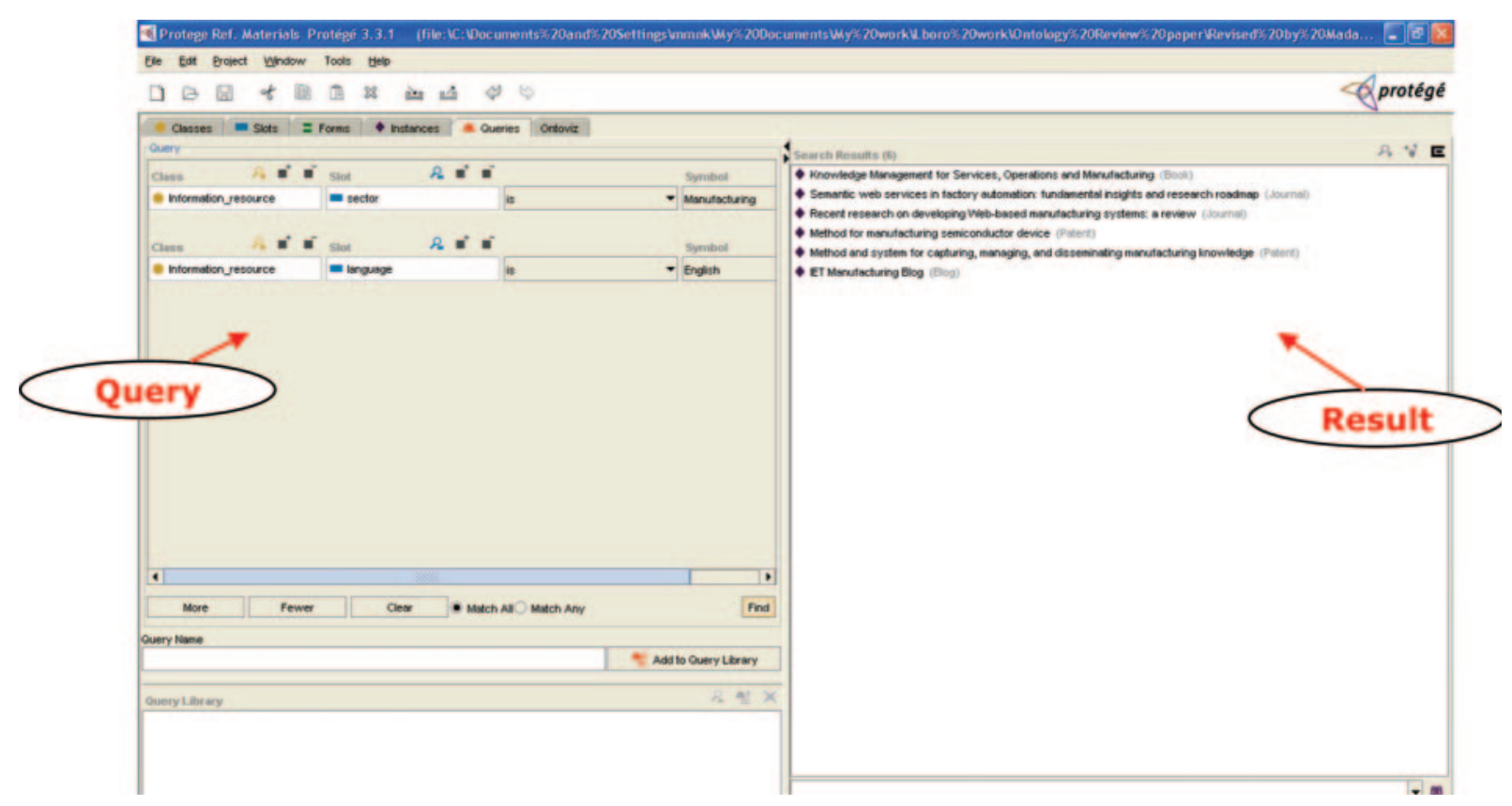

Fig. 9 A screen shot of querying knowledge base in Protege

integration. The aim is effectively to manage the present and shape the future, providing a consistent route towards continuous improvement. Information flow is a major requirement for effective and efficient working in the manufacturing domain. For effective information exchange in distributed manufacturing environments, it is necessary to maintain compatibility and preserve syntactic and semantic content during the exchange of messages. Web technology and web services have been widely employed in different sections of the manufacturing domain. Various web-based manufacturing systems have been developed in the past decade for supporting activities in different parts of a manufacturing life cycle, including marketing, design, planning, production, distribution, service, etc. The role of the web in manufacturing shows that interoperability is a central issue in the manufacturing domain. Web technology is unable to solve the issue of interoperability among heterogeneous systems. Therefore, the concept of ontological engineering has been developed to aim for the ultimate goal of seamless manufacturing system integration.

Ontologies and semantic web are currently being employed to solve these requirements of integration and collaboration. Apart from ontologies, massive research is going on into semantic web services. Semantic web services are used to interoperate multiple ontologies dealing with multiple domains. This paper provides a brief survey of the research work in the manufacturing domain using ontology and semantic web for integration and interoperability. Ontologies are useful for communicating information and relationships, but it can be very difficult to integrate them with other problem solving techniques. Moreover, it is difficult to manage large and complex ontologies. A problematic issue arises when attempts are made to integrate ontologies that contradict each other. Semantic mapping between ontologies such as ontology mapping, term mapping, ontology translation, etc. may be used to resolve this problem, but these can be complex and time-consuming activities. Semantic web services are used to work with multiple ontologies and identify patterns among ontologies belonging to different domains. A significant amount of research is required to achieve a semantic environment for manufacturing system services, even though the importance of the semantic web services has been recognized and widely accepted by industry and academic research. However, the two worlds have proposed solutions that progress along different dimensions. Academic research has been mostly concerned with expressiveness of service descriptions, while industry has focused on modularization of service layers for usability in the short term. The development of semantic enhanced web services for a domain should be carried out as joint venture research by academia and industry. This converged effort will leverage knowledge of systems with the required practical and theoretical aspects.

\section{REFERENCES}

1 Vernadat, F. B. Enterprise modeling and integration (EMI): current status and research perspectives. A. Rev. Control, 2002, 26, 15-25. 
2 Linthicum, D. S. Enterprise application integration, 1999 (Addison-Wesley, New York).

3 Virtual enterprise, available online at http://www.samcom.com.au/papers/16.pdf.

4 Gialelis, J. V., Kalogeras, A. P., Alexakos, C. E., and Papadopoulos, G. Manufacturing collaborative process integration utilizing state of the art technologies. Proceedings of the IEEE International Symposium on Industrial electronics, ISIE 2005, Vol. 4, pp. 1429-1434.

5 Harding, J. A., Yu, B., and Popplewell, K. Information modelling: an integration of views of a manufacturing enterprise. Int. J. Prod. Res., 1999, 37, 2777.

6 Huang, N. and Diao, S. Ontology based enterprise knowledge integration. Robotics and Computer Integr. Mfg, 2008, 24(4), 562-571.

7 Lutters, D., Mentink, R. J., van Houten, F. J. A. M., and Kals, H. J. J. Workflow management based on Information Management. CIRP Annls - Mfg Technol., 2001, 50, 309-312.

8 Howells, R. ERP needs shop-floor data. Mfg Engng, 2000, 10, 54-62.

9 Cochrane, S., Young, R., Case, K., Harding, J., Gao, J., Dani, S., and Baxter, D. Knowledge reuse in manufacturability analysis. Robotics and Computer Integr. Mfg, 2008, 24(4), 508-513.

10 Zhou, Jiehan. Manufacturing ontology analysis and design: towards excellent manufacturing. Second IEEE International Conference on Industrial informatics, INDIN '04, 2004, pp. 39-45.

11 Casey, M. and Pahl, C. Web components and the semantic web. Electron. Notes in Theoret. Computer Sci., 2003, 82, 156-163.

12 Burstein, M. A semantic web services architecture. Internet Computing, IEEE, 2005, 9, 72-81.

13 Berners-Lee, T., James, H., and Ora, L. The semantic web. Sci. Am. Mag., 2001, 34-43.

14 Terziyan, V. and Kononenko, O. Semantic web enabled web services state-of-art and industrial challenges. ICWS-Europe 2003, LNCS 2853, 2003, pp. 183-197.

15 Wei, C. and Hao, W. Using ontology to achieve the semantic integration and interoperation of GIS. In Proceedings of the 2005 IEEE International Geoscience and remote sensing symposium, IGARSS '05, 2005, Vol. 2, p. 3.

16 Laurent, D. and Jean-François, R. Towards semantic modelling for manufacturing product life cycle. In Proceeding of Conference C2IE, Nancy, France, 1-2 December 2004, Paper S1-D.

17 Canavesio, M. M. and Martinez, E. Enterprise modeling of a project-oriented fractal company for SMEs networking. Computers in Ind., 2007, 58, 794-813.

18 Tidwell, D. Web services-the web's next revolution, IBM Tutorial, June, 2000.

19 Cerami, E. Web services essentials, 2002 (O'Reilly Media). ISBN: 10:0-596-00224-6.

20 Delamer, I. M. A peer-to-peer discovery protocol for semantic web services in industrial embedded controllers. In Proceeding of the 31st Annual Conference of IEEE Industrial electronics society, IECON 2005, p. 7.

21 Guha, R. and McCool, R. Tap: the semantic platform. Computer Networks, 2003, 42, 557-577.

22 Jiehan, Zhou. A survey on semantic web services and a case study. In Proceeding of the Tenth International
Conference on Computer supported cooperative work in design, CSCWD '06, 2006, pp. 1-7.

23 Lammari, N. and Metais, E. Building and maintaining ontologies: a set of algorithms. Data and Knowledge Engng, 2004, 48, 155-176.

24 Yoshinobu, K. and Riichiro, M. Ontology-based systematization of functional knowledge. J. Engng Des., 2004, 15, 327-351.

25 Zhou, J. and Dieng-Kuntz, R. Manufacturing ontology analysis and design: towards excellent manufacturing. INDIN '04, 2004, pp. 39-45.

26 Gottgtroy, P., Kasabov, N., and MacDonell, S. evolving ontologies for intelligent decision support Fuzzy logic and the semantic web. In Capturing intelligence (Ed. E. Sanchez), 2006, Vol.1, pp. 415-439 (Elsevier, Amsterdam).

27 Neches, R., Fikes, R., Finin, T., Gruber, T., Patil, R., Senatir, T., and Swartout, W. Enabling technology in knowledge sharing. AI Mag., 1991, 12, 36-56.

28 Gruber, T. R. A translation approach to portable ontologies. Knowledge Acquisition, 1993, 5, 199-220.

29 Borst, W. N. Construction of engineering ontologies, 1997 (Enschede, The Netherlands).

30 Guarino, N. and Giaretta, P. Ontologies and knowledge bases: towards a terminological clarification. In Towards very large knowledge bases: knowledge building and knowledge sharing (Ed. N. Mars), 1995, pp. 25-32.

31 Guarino, N. (Ed.) Formal ontology in information systems. In Proceedings of FOIS, Trento, Italy, 1998, 3-15.

32 Bernaras, A., Laresgoiti, I., and Corera, J. Building and reusing ontologies for electrical network applications. ECAI'96 (Budapest, Hungary), 1996, pp. 298-302.

33 Swartout, B., Patil, R., Knight, K., and Russ, T. Toward distributed use of large scale ontologies. In Proceedings of Symposium on Ontology engineering, 1997, 138-148.

34 Uschold, M. and Jasper, R. A framework for understanding and classifying ontology applications, In Proceedings of the Twelth Workshop on Knowledge Acquisition Modelling and Management KAW99, 1999.

35 Gomez-Perez, A., Fernandez-Lopez, M., and Corcho, 0. Ontological engineering, London: Springer-Verlag, 2004.

36 Gandon, F. Distributed artificial intelligence and knowledge management: ontologies and multi-agent systems for a corporate semantic web. PhD Thesis in Informatics, 2002. http://www.sop.inria.fr/acacia/ personnel/Fabien.Gandon/research/PhD2002/.

37 Merdan, M., Kordic, V., Zoitl, A., and Lazinica, A. Knowledge-based multi-agent architecture. In Proceeding of the International Conference on Computational intelligence for modelling control and automation, and international conference on intelligent agents, web technologies and internet commerce (CIMCA-IAWTIC'06), Sydney, Australia, 2006 (IEEE Computer Society, Washington, USA).

38 Merdan, M. Intelligent reconfiguration using knowledge based agent system. In Proceedings of the 10th IEEE Conference on Emerging technologies and factory automation, ETFA 2005, Vol. 1, p. 4.

39 Pouchard, L. and Rana, O. The role of ontologies in agent-oriented systems. In Proceedings of the Sixth Joint Conference on Information Sciences, Computational Semiotics Workshop, North Carolina, 2002. 
40 Celik, D. A semantic search agent approach: finding appropriate semantic web services based on user request term(s). In Proceedings of the ITI 3rd International Conference on Information and communications technology, enabling technologies for the new knowledge society, 2005, pp. 675-687.

41 Nabuco, O., Rosário, J. M., Silva, J. R., and Drira, K. Scientific collaboration and knowledge sharing in the virtual manufacturing network. In Proceedings of the International federation of automatic control, conference, Salvador, Brazil, 2002.

42 Yang, H. and Xue, D. Recent research on developing web-based manufacturing systems: a review. Int. J. Prod. Res., 2003, 41, 3601.

43 Zhou, J. and Dieng-Kuntz, R. Manufacturing ontology analysis and design: towards excellent manufacturing. In Proceedings of the Second IEEE International Conference on Industrial informatics, INDIN '04, Berlin, Germany, 2004, pp. 39-45 (IEEE Computer Society).

44 Dori, D. and Shpitalni, M. Mapping knowledge about product lifecycle engineering for ontology construction via object-process methodology. CIRP Annls, Mfg Technol., 2005, 54, 117-122.

45 Suárez, S., Lopez, B., and Melendez, J. Towards holonic multiagent systems: ontology for supervision tool boxes, 2008. http://citeseerx.ist.psu.edu/viewdoc/summary10. 1.1.127.6792.

46 Lin, H. K. and Harding, J. A. A manufacturing system engineering ontology model on the semantic web for inter-enterprise collaboration. Computers in Ind., 2007, 58, 428-437.

47 Kim, W. and Chung, M. Collaboration in design and manufacturing process using web services semantics. In Proceedings of the 9th International Conference on Computer supported cooperative work in design proceedings, Paris, France, 2005 (Springer, The Netherlands).

48 Nanda, J., Simpson, T. W., Kumara, S. R. T., and Shooter, S. B. A methodology for product family ontology development using formal concept analysis and web ontology language. J. Computing Inf. Sci. Engng, 2006, 6, 103-113.

49 Lee, H. M., Gay, R., and Lu, W. The framework of information sharing in end-of-life for sustainable product development. In Proceedings of the IEEE International Conference on Industrial informatics, Singapore, 2006, pp. 73-78 (IEEE).

50 Yang, Q. Z., Miao, C. Y., and Zhang, Y. Ontology modelling and engineering for product development process description and integration. In Proceedings of the IEEE International Conference on Industrial informatics, Singapore, 2006, pp. 85-90 (IEEE).

51 Delamer, I. M. Ontology modeling of assembly processes and systems using semantic web services. In Proceedings of the IEEE International Conference on Industrial informatics, Singapore, 2006, pp. 611-617 (IEEE).

52 Zhang, W. Y., Lin, L. F., Tong, R. F., Li, X., and Dong, J. X. B-FES/o: an ontology-based scheme for functional modeling in design for semantic web applications. The 9th International Conference on Computer supported cooperative work in design proceedings, Coventry, UK, 2005 (Lecture Notes in Computer Science).
53 Obitko, M. and Marik, V. Ontologies for multi-agent systems in manufacturing domain. Proceedings of 13th International Workshop on Database and expert systems applications-DEXA'02, Aix-en-Provence, France, 2002 (IEEE Computer Society).

54 Merdan, M., Terzic, I., and Zoitl, A. Intelligent reconfiguration using knowledge based agent system. Tenth IEEE Conference on Emerging technologies and factory automation, ETFA 2005, Catania, Italy, Vol. 1, p. 4 (IEEE).

55 Xin Jin. Ontology-driven coordination for supply chain system. Proceedings of 2005 IEEE International Conference on Natural language processing and knowledge engineering, IEEE NLP-KE '05, Wuhan, People's Republic of China, pp. 331-335 (IEEE Computer Society).

56 Mönch, L. and Stehli, M. An ontology for production control of semiconductor manufacturing processes. Lecture Notes in Computer Sci., 2004, 2831, 1097.

57 Schlenoff, C., Denno, P., Ivester, R., Libes, D., and Szykman, S. An analysis and approach to using existing ontological systems for applications in manufacturing. AI- EDAM, 2000, Vol. 14, pp. 257-270.

58 Thatte, S. XLANG: Web services for business process design, microsoft corporation, 2001, available online at http://www.gotdotnet.com/team/xml_wsspecs/xlang-c/ default.htm.

59 McDermott, D. and Dou, D. Representing disjunction and quantifiers in Rdf. In Proceedings of International Semantic Web Conference, Sardinia, Italy, 2002, pp. 250-263.

60 Fox, M. S. and Gruninger, M. Enterprise modeling. $A I$ Mag., 1998, 19, 109-121.

61 Schlenoff, C. and Uschold, M. Knowledge engineering and ontologies for autonomous systems: 2004 AAAI Spring Symposium. Robotics and Autonomous Systems, 2004, 49, 1-5.

62 Goossenaerts, J. B. M. and Pelletier, C. Ontology and enterprise modelling. In Participative simulation environment for integral manufacturing enterprise renewal (Ed. Eijnatten), 2002, pp. 41-52 (TNO Arbeid, Amsterdam, The Netherlands).

63 Fadel, F., Fox, M. S., and Gruninger, M. A generic enterprise resource ontology. In Proceedings of the Third Workshop on Enabling technologies - infrastructures for collaborative enterprises, 1994, pp. 86-92.

64 Arkin, A. Business process modeling language (BPML), Working Draft 0.4, 2001, available online at http://www. bpmi.org/.

65 Waldt, D. and Drummond, R. EBXML: the global standard for electronic business, available online at http:// www.ebxml.org/presentations/global_standard.htm.

66 Corcho, O., Fernandez-Lopez, M., and Gomez-Perez, A. Methodologies, tools and languages for building ontologies. Where is their meeting point? Data \& Knowledge Engng, 2003, 46, 41-64.

67 Gómez-Pérez, A. and Suárez-Figueroa, M. C. E. Evaluation of RDF(S) and DAML+OIL import/export services within ontology platforms. Advances in artifical intelligence, 2004, Vol. 2972, pp. 109-118.

68 Liu, Y. Implementation of supply chains coordination using semantic web service composition. IEEE International Conference on Service-oriented computing 
and applications, SOCA '07, Newport Beach, California, 2007, pp. 249-254 (IEEE Computer Society).

$69 \mathrm{Xu}$, H. and Xiao, D. Applying semantic web services to automate network management. In Proceedings of the Second IEEE Conference on Industrial electronics and applications, ICIEA 2007, Harbin, People's Republic of China, pp. 461-466.

70 Kulvatunyou, B. and Ivezic, N. Semantic web for manufacturing web services. Proceedings of the 5th Biannual World, Automation Congress, Seville, Spain, 2002, Vol, 14, pp. 597-606.

71 Yang, Z., Gay, R., Miao, C., and Shen, Z. Automating integration of manufacturing systems and services: a semantic web services approach. In Proceedings of the 31st IEEE Annual Conference on Industrial electronics society, North Carolina, USA, IECON 2005, p. 6 (IEEE).

72 Chen, G. and Zhang, J. B. Collaborative virtual enterprise integration via semantic web service composition. In Proceedings of the Second IEEE Conference on Industrial electronics and applications, ICIEA 2007, Harbin, People's Republic of China, pp. 1409-1414 (IEEE).

73 Lastra, J. L. M. Semantic web services in factory automation: fundamental insights and research roadmap. IEEE Trans. Ind. Infomatics, 2006, 2, 1-11.

74 Devedzic, V. A framework for building intelligent manufacturing systems. IEEE Trans. Systems, Man, and Cybernetics, Part C: Applic. Rev., 1999, 29, 422-439.

75 Intelligent Manufacturing Systems, 1996. Available online at http://www.img.org.
76 Muata, K., Bryson, O., and Grant, D. A manufacturing information systems architecture for the 21st century. In Proceedings of the Sixth International Conference on Enterprise Information Systems, Porto, Portugal, 14-17 April 2004, pp. 457-463 (American Association for Artifical Intelligence, Menlo Park, California).

77 Lutters, D., Mentink, R. J., van Houten, F. J. A. M., and Kals, H. J. J. Workflow management based on information management. CIRP Annls, Mfg. Technol., 2001, 50, 309-312.

78 True, M. and Izzi, C. Collaborative product commerce: creating value across the enterprise. Ascet, 2002, White Paper.

79 Simpson, T. W. Product platform design and customization: status and promise. Artificial Intell. Engng Des., 2004, 18, 3-20.

80 Lagrosen, S. Quality management in global firms. The TQM Mag., 2004, 16(6), 396-402.

81 Khilwani, N., Harding, J. A., and Tiwari, M. K. Ontology mining for platform extraction in product development. In Proceedings of the 14th International Conference on Concurrent engineering, 2008, available online at http:// www.itaide.org/Projects/480/ICE\%202008/Review\% 20Process/Final\%20papers\%20ICE\%202008/ Final-Paper\%20ICE\%202008.doc.

82 Dejing Dou, Drew McDermott, and Peishen Qi, Ontology translation on the semantic web. In Proceedings of International Conference on Ontologies, databases and applications of semantics (ODBASE2003) LNCS 2888, Catania, Italy, 2003, pp. 952-969.

\section{APPENDIX A: Information Resource Ontology model}

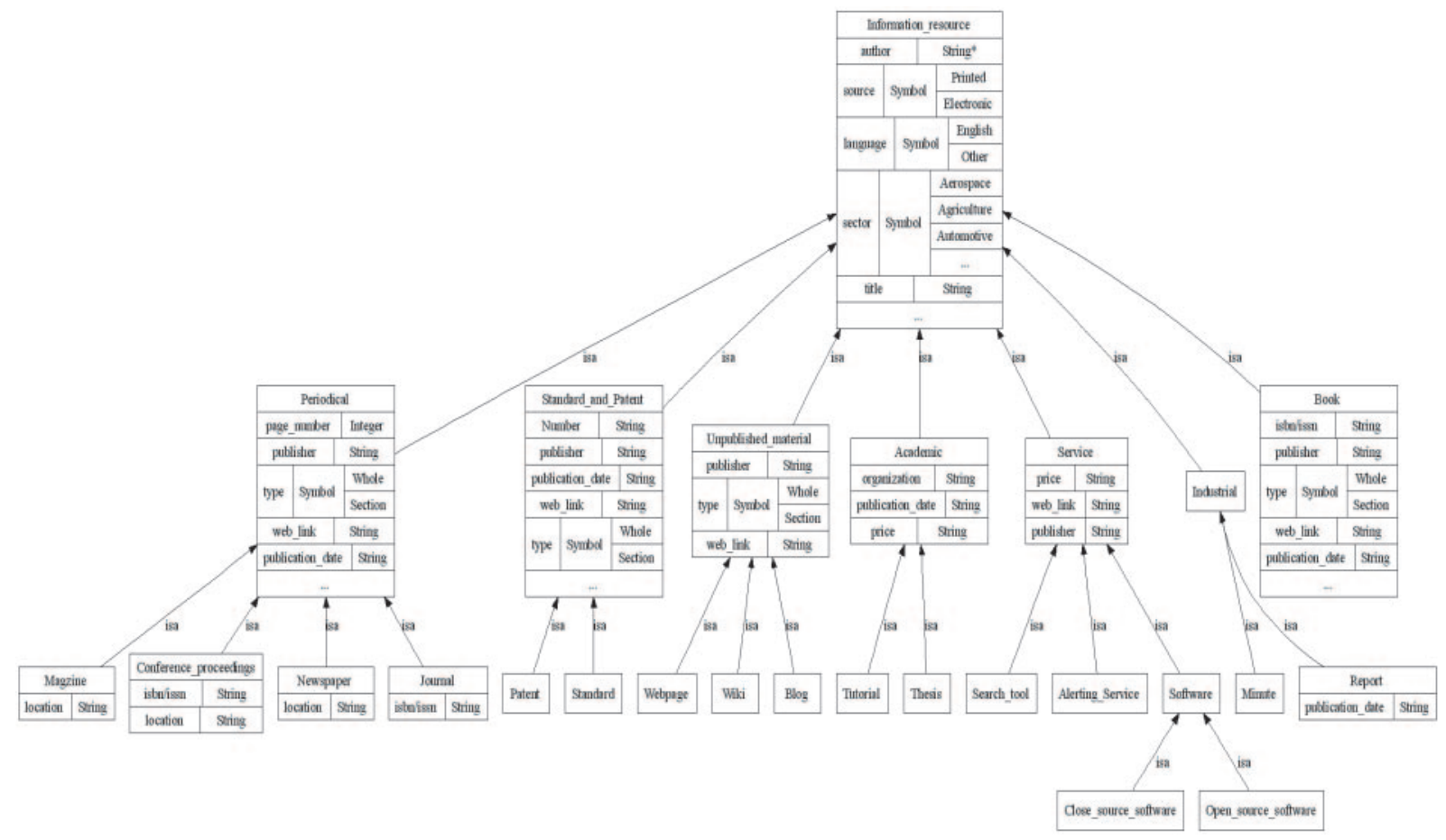

